\title{
Does the Brain Extrapolate the Position of a Transient Moving Target?
}

\author{
Julie Quinet and $\odot$ Laurent Goffart \\ Institut de Neurosciences de la Timone, Unité Mixte de Recherche, 7289 Centre National de la Recherche Scientifique, Aix-Marseille Université, 13385 \\ Marseille Cedex 5, France
}

When an object moves in the visual field, its motion evokes a streak of activity on the retina and the incoming retinal signals lead to robust oculomotor commands because corrections are observed if the trajectory of the interceptive saccade is perturbed by a microstimulation in the superior colliculus. The present study complements a previous perturbation study by investigating, in the head-restrained monkey, the generation of saccades toward a transient moving target (100-200 ms). We tested whether the saccades land on the average of antecedent target positions or beyond the location where the target disappeared. Using target motions with different speed profiles, we also examined the sensitivity of the process that converts time-varying retinal signals into saccadic oculomotor commands. The results show that, for identical overall target displacements on the visual display, saccades toward a faster target land beyond the endpoint of saccades toward a target moving slower. The rate of change in speed matters in the visuomotor transformation. Indeed, in response to identical overall target displacements and durations, the saccades have smaller amplitude when they are made in response to an accelerating target than to a decelerating one. Moreover, the motion-related signals have different weights depending upon their timing relative to the target onset: early signals are more influential in the specification of saccade amplitude than later signals. We discuss the "predictive" properties of the visuo-saccadic system and the nature of this location where the saccades land, after providing some critical comments to the "hic-et-nunc" hypothesis (Fleuriet and Goffart, 2012).

Key words: adaptation; extrapolation; interception; prediction; saccade; visual motion

\section{Significance Statement}

Complementing the work of Fleuriet and Goffart (2012), this study is a contribution to the more general scientific research aimed at understanding how ongoing action is dynamically and adaptively adjusted to the current spatiotemporal aspects of its goal. Using the saccadic eye movement as a probe, we provide results that are critical for investigating and understanding the neural basis of motion extrapolation and prediction.

\section{Introduction}

The sudden appearance of an object in the peripheral visual field triggers a saccadic movement of the eyes that quickly orients the two foveae toward its location. By bringing the object's image within the foveal field, the orienting saccade increases the mass of activated neurons (Johnston, 1986), for example, in visual areas

Received March 28, 2015; revised June 29, 2015; accepted July 7, 2015.

Author contributions: L.G. designed research; J.Q. and L.G. performed research; J.Q. and L.G. analyzed data; J.Q. and L.G. wrote the paper.

This work was supported by the Centre National de la Recherche Scientifique, the Agence Nationale de la Recherche (Grant VISAFIX), the European Research Council (grant position to Prof. Patrick Cavanagh), and the Fondation de France (Berthe Fouassier Grant 0039352 to J.Q.). We thank Marc Martin and Ivan Balansard for veterinarian care, Xavier Degiovanni for technical assistance, Ivo Vanzetta and Frédéric Chavane for each lending us one of their monkeys, and the reviewers for insightful and constructive comments.

The authors declare no competing financial interests.

Correspondence should be addressed to Laurent Goffart, INT, UMR 7289 CNRS-AMU, Campus Santé, 27 Bd Jean Moulin, 13385 Marseille Cedex 5, France. E-mail: laurent.goffart@univ-amu.fr.

DOI:10.1523/JNEUROSCI.1212-15.2015

Copyright $\odot 2015$ the authors $\quad 0270-6474 / 15 / 3511780-11 \$ 15.00 / 0$ of the cerebral cortex (Daniel and Whitteridge, 1961; Van Essen et al., 1984; Albright and Desimone, 1987; Tootell et al., 1988) and in the rostral superior colliculi (SC) (McIlwain, 1976). This recruitment of more neurons favors the identification of the object and its pursuit when it is moving (Newsome et al., 1985; Segraves et al., 1987). Concerning the localization of the object, the flow of neural activity that leads to the completion of a saccade can be viewed as a neurobiological estimate of its physical location because the saccade endpoints covary with the target locations. The localization is not a discrete ballistic process that ends at saccade onset. Indeed, unexpected perturbations in saccade trajectory can be rapidly compensated so that the gaze is ultimately directed toward the physical target location (Schiller and Sandell, 1983; Sparks and Mays, 1983; Gandhi and Keller, 1999; Goossens and van Opstal, 2000; Xu-Wilson et al., 2011). In fact, the visuo-oculomotor localization is a continuous process (McPeek et al., 2000; McPeek and Keller, 2001) that is complemented by postsaccadic cerebellar (Guerrasio et al., 2010; Arn- 

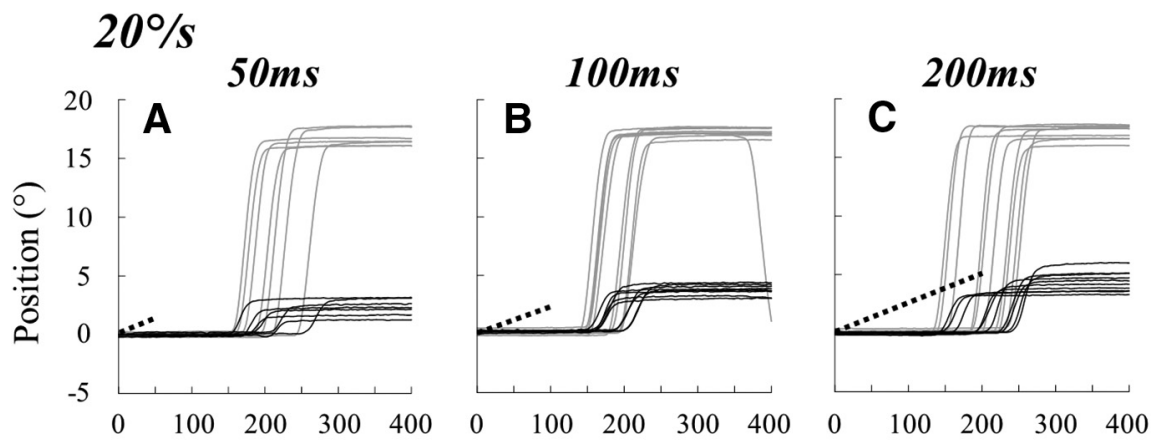

the average of positions that the target occupied during the presaccadic period or if they land beyond the location where the target disappeared, revealing, in that case, some "extrapolation" capabilities of the visuo-saccadic system. To further examine the sensitivity of a presumed temporal integration process to the target motion dynamics, we also tested different target speed profiles. Our results support the view that the brain converts a brief retinal streak of activity into a saccade endpoint according to a dynamic process that, in
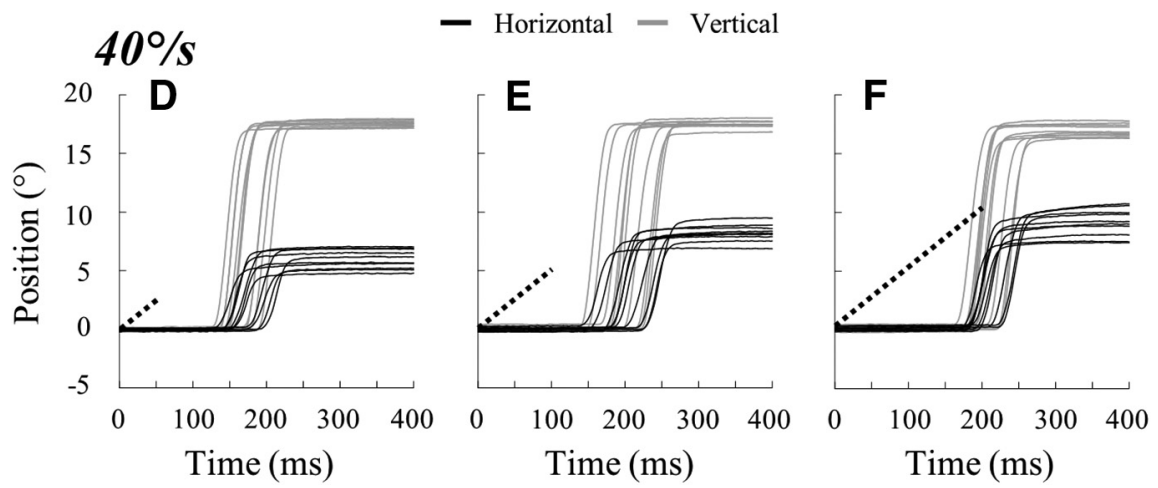

Figure 1. Time course of saccades toward a transient target moving with a constant speed. The eye position (horizontal: black; vertical: gray) is plotted as a function of time after the onset of a target that moves in the upper right quadrant with a constant speed ( $\left.\boldsymbol{A}-\boldsymbol{C}: 20^{\circ} \mathrm{s} ; \boldsymbol{D}-\boldsymbol{F}: 40^{\circ} / \mathrm{s}\right)$ and for different durations: $50 \mathrm{~ms}(\boldsymbol{A}, \boldsymbol{D}), 100 \mathrm{~ms}(\boldsymbol{B}, \boldsymbol{E})$, and $200 \mathrm{~ms}(\boldsymbol{C}, \boldsymbol{F})$. The time course of target position is illustrated by the dotted black line. The selected saccades were recorded in the Monkey A. Figure $2 E$ shows that the horizontal undershoot of saccades shown in Figure $2 F$ is due to the selection.

stein et al., 2015), collicular (Goffart et al., 2012; Hafed and Krauzlis, 2012) and medullar activities (Mettens et al., 1994; Dale and Cullen, 2015) that maintain the object image within the central visual field.

When the object moves in the visual field, its motion evokes a streak of activity on the retina and the resulting visual signals are obviously different from those elicited by a static object. However, this fleeting activity also leads to robust oculomotor commands because corrections are observed in the monkey when the saccade trajectory is perturbed by a brief microstimulation in the deep SC (Fleuriet and Goffart, 2012). In this study, the change of trajectory occurred $150 \mathrm{~ms}$ after the onset of the target motion and during a short blank interval (150 or $300 \mathrm{~ms}$ ). Because the corrections were made in the absence of visual feedback, the hypothesis was proposed that the gaze was guided by an estimate of the expected and current spatiotemporal position of the target. Two groups of signals can participate in the elaboration of this command and guide the saccades toward the transiently invisible moving target regardless of whether their trajectory is perturbed or not: (1) the target-motion-related signals that precede the blank interval and (2) the mnemonic signals that the target is expected to reappear and continue to move along the same path. A sort of interpolation would happen when the spread of target related activity (e.g., in the deep SC; Sparks et al., 1976; Anderson et al., 1998) merges with upcoming expected visual signals (Walker et al., 1995), "filling" the blank interval with a neural signal that would drive the gaze motor system.

The present work is focused on testing the influence of the first group of signals (those that precede the blank) in the specification of the saccade endpoint. More specifically, we tested whether saccades made in response to a transient moving target land on

\section{ments were approved by the Regional Ethics} Committee (approval no. A13/01/13) and conducted in compliance with the guidelines of the European Community on Animal Care under the auspices of a full-time veterinarian.

Eye movement recording and visual stimulation. Data acquisition, online control of oculomotor performance, and triggering of stimuli were controlled by a PC using the Beethoven software package (Ryklin Software). Eye movements were measured with a phase angle detection system (3-feet coil frame; CNC Engineering). Voltage signals separately encoding horizontal and vertical positions of the eye were sampled at 500 Hz. Monkeys were seated in a chair facing a video monitor (Samsung SyncMaster 2233; $100 \mathrm{~Hz}$ refresh rate) located at a viewing distance of 38 $\mathrm{cm}$. Visual stimuli were Gaussian-blurred disks of $0.4^{\circ}$ diameter.

Behavioral tasks. Experiments were conducted in a dark room essentially illuminated by the gray background of visual display. The monkeys were seated in a primate chair with the head restrained. Eye position signals were calibrated by having the animal fixate stationary targets presented at $\pm 16^{\circ}$ along the horizontal or vertical meridians.

Each animal was first trained to perform a saccade task that shifted gaze from a central (straight-ahead) target toward another static target. For each trial, a warning tone preceded the onset of the central target. The monkey's task was to direct and maintain its gaze within a spatial window ( $4^{\circ}$ radius) surrounding the target for a variable interval $(750-1500 \mathrm{~ms}$ varied in increments of $250 \mathrm{~ms}$ ). The size of the fixation window was large to avoid constraining the oculomotor behavior within artificial limits. This strategy turned out to be very helpful in detecting any fixational bias without frustrating the animal with a trial cancel (Goffart et al., 2006). Moreover, the duration of the fixation interval is long and we have reported previously that, despite the large size of acceptance windows and a relatively extended fovea, the area of "foveal exploration" is rather limited (Guerrasio et al., 2010). After the fixation interval, the central target was extinguished and, immediately after, the peripheral target was presented in the upper or lower field with a vertical eccentricity (Cartesian coordinates) of $16^{\circ}$ (upward or downward) and various randomly 
selected horizontal eccentricities $\left(1^{\circ}, 2^{\circ}, 3^{\circ}, 4^{\circ}\right.$, $5^{\circ}, 6^{\circ}$, and $8^{\circ}$ leftward or rightward). After sufficient data ( $>100$ saccades per target location) were collected to estimate the oculomotor localization of each target, the monkeys were exposed to a second series of experiments in which they had to make saccades toward a transient moving target. After the same fixation interval, the central target was extinguished and, immediately after, the peripheral target moved in a direction orthogonal to the vertical meridian rightward or leftward (random selection) with a constant speed of $20 \%$ s. The duration of the target motion was very short on the first day $(50 \mathrm{~ms})$. It was increased to $100 \mathrm{~ms}$ on the second day, $200 \mathrm{~ms}$ on the third day, $400 \mathrm{~ms}$ on the fourth day, and $800 \mathrm{~ms}$ on the fifth day. This block design was used to ensure that the monkeys did not adapt the size of their saccades based on postsaccadic visual signals (Hopp and Fuchs, 2004) and transfer their learning either to the saccades made toward the briefer targets or to those generated during the next testing day. Moreover, the experiments reported here are the first component of a larger research program the goal of which is to examine how the ability to maintain the image of a moving target onto the foveae (during pursuit eye movement) evolves as a function of practice (Bourrelly et al., 2014) and to study the conditions required to build up an "internal model" of a moving target (Goffart et al., 2014). Different target speeds were tested afterward. The next tested speeds were $10 \% \mathrm{~s}$ and $40 \%$ (constant speed). Increasing and decreasing speeds were also tested. In those tests, the target speed increased linearly from 0 to $40 \% \mathrm{~s}($ or $80 \%$ ) or decreased linearly from $40 \%$ ( or $80 \%$ ) to $0 \%$ s during $200 \mathrm{~ms}$ (or $100 \mathrm{~ms}$ ). The monkeys were rewarded 100-300 ms after they directed their gaze within an ellipsoidal spatial window around the moving target. The size of the window was adjusted so that the monkeys were always rewarded after each saccade made in the appropriate visual quadrant.

Data analysis. All data were digitized online and analyzed offline using a software program that detected the onset and offset of the horizontal and vertical saccade components on the basis of velocity threshold $(15 \%$ s). The same velocity threshold was used to quantify the saccades made toward a static and a moving target. The $15 \%$ value was kept because the animals did not exhibit postsaccadic slow eye movement when the target moved during $200 \mathrm{~ms}$ or less. Indeed, the results of the automatic detection were checked individually by inspecting the time course and the trajectory of the eye during each trial. Several parameters, such as the amplitude, landing position, and time, were extracted automatically from detected movements. Statistical values reported in the Results section correspond to the median \pm interquartile range. Unless stated otherwise, this work focus on saccades made toward a target that moved for $200 \mathrm{~ms}$ or less. In some analyses, the saccade endpoints are considered regardless of the quadrant of the visual field that was traveled by the target. For grouping together the numerical values corresponding to leftward and rightward eye positions, the position values were multiplied by -1 when the eye was deviated toward the left.

\section{Results}

Figure 1 shows the time course of the horizontal and vertical components of oblique saccades made in response to a target that moves in the upper right quadrant with a constant speed (top: $20 \%$; bottom: $40 \%$ s) and for durations that range from $50 \mathrm{~ms}$ (leftmost graphs) to $200 \mathrm{~ms}$ (rightmost graphs). Dou-

\section{$2^{\circ}$ target displacement}

Monkey $M$

.... Static target - 50ms@ $40 \%$ - 100ms @ 20\%
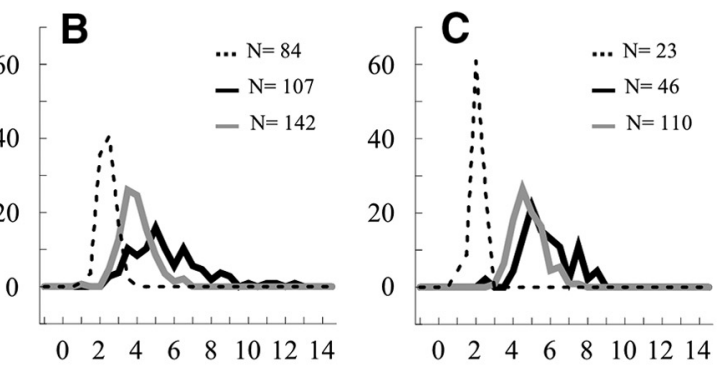

$4^{\circ}$ target displacement

.... Static target - 100ms@40\% - 200ms@20\% $\left({ }^{\circ}\right)$

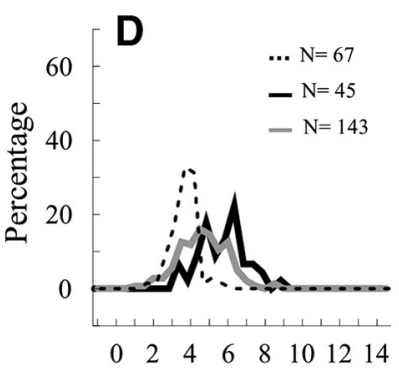

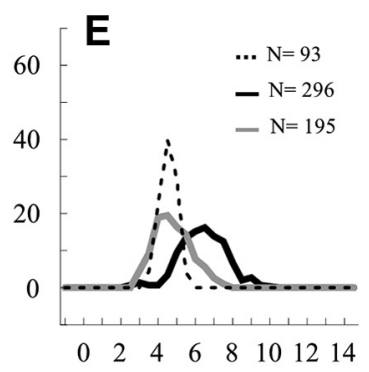

Hor. final position $\left({ }^{\circ}\right)$

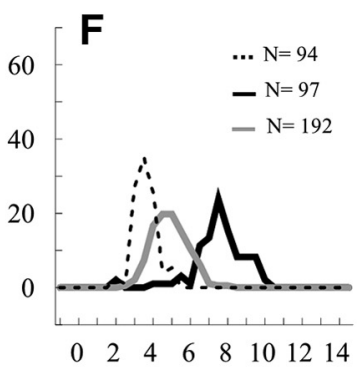

Hor. final position $\left(^{\circ}\right)$
Figure 2. Distribution of the horizontal positions of saccade endpoints. For each monkey (Monkey G: left; Monkey A: middle; and Monkey M: right), the distribution of the horizontal final positions is shown for all saccades made in response to a target that moved in the upper right quadrant for a $2^{\circ}(\boldsymbol{A}-\boldsymbol{C})$ or a $4^{\circ}(\boldsymbol{D}-\boldsymbol{F})$ overall displacement. Dashed line indicates a static target; solid dark line, a target moving at $40 \%$; and solid gray line, a target moving at $20 \% \mathrm{~s}$ (constant speeds).

bling the duration of target motion slightly enhances the horizontal amplitude of saccades (e.g., compare graph B vs graph A or graph $\mathrm{E}$ vs graph $\mathrm{D}$ ), but the effect is not as strong as the effect of doubling the target speed. Indeed, for identical durations of target motion, the horizontal amplitude is larger when the target moves faster (e.g., compare graph D vs graph A or graph $\mathrm{E}$ vs graph $\mathrm{B}$ ). This amplitude increase is not due to the mere fact that the target displacement is larger. When we compare saccades made in response to identical overall target displacements but with different speeds, the horizontal amplitude is still larger when the target moves faster, even though the motion duration is half as long (compare graph D vs graph $\mathrm{B}$ and graph $\mathrm{E}$ vs graph $\mathrm{C}$ ).

Figure 2 shows for each monkey the distribution of the horizontal positions of saccade endpoints when the target moves in the same upper right quadrant. The horizontal amplitude of the target displacement amounts to $2^{\circ}$ in the histograms of the upper row (Fig. $2 A-C$ ) and to $4^{\circ}$ in the lower row (Fig. $2 D-F$ ). The final horizontal positions of saccades toward a static target presented at the location where the moving target disappeared (i.e., $16^{\circ}$ upward, $2^{\circ}$ and $4^{\circ}$ to the right) are also shown for comparison. Although the visual activity elicited by the target motion is spatially asymmetric, it is noticeable that the values of horizontal position are symmetrically distributed for saccades toward a moving target. Second, considering the saccades made in response to the $2^{\circ}$ target displacement, the horizontal final positions are significantly more eccentric when the target moves at $40 \%$ during $50 \mathrm{~ms}$ than when it moves at $20 \% \mathrm{~s}$ during $100 \mathrm{~ms}$ in 
$2^{\circ}$ target displacement
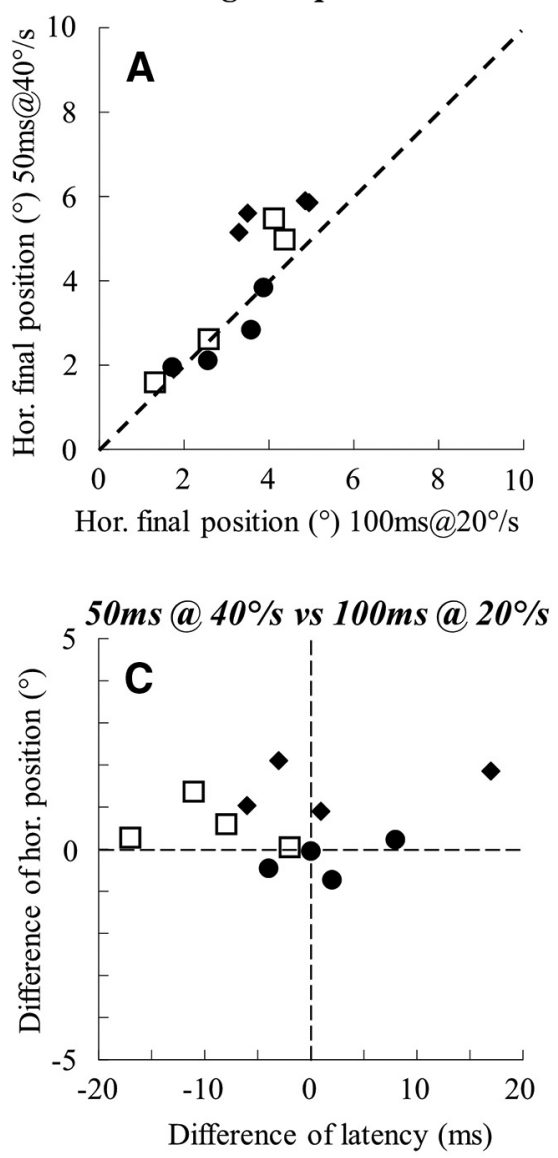

$4^{\circ}$ target displacement
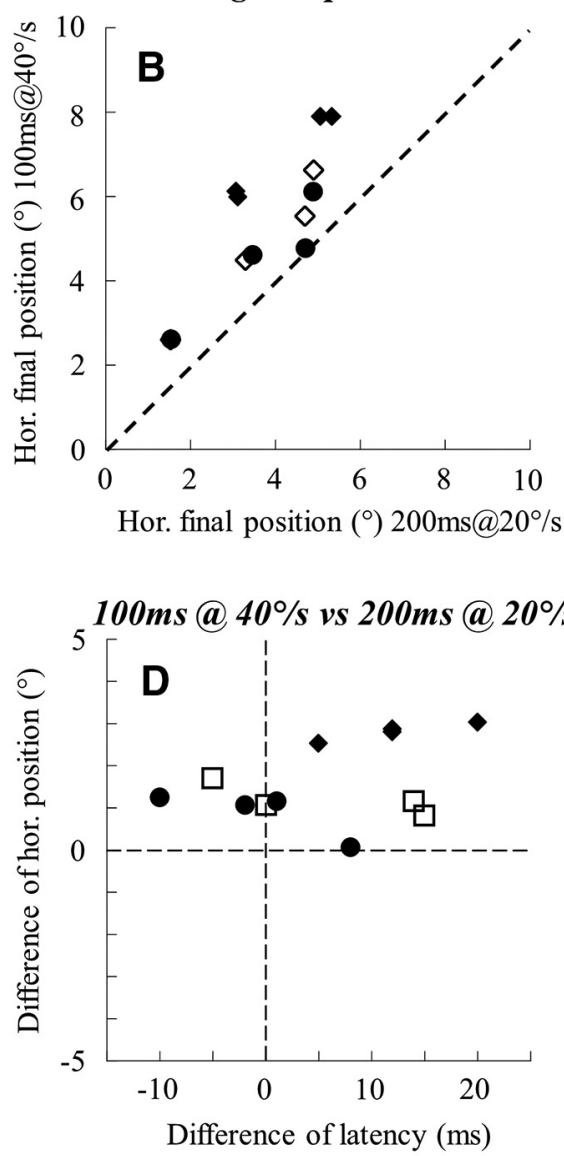

\section{- Monkey G $\square$ Monkey A $\bullet$ Monkey M}

Figure 3. Influence of target speed on final eye position. Top, Horizontal final positions of saccades toward a target moving at $20^{\circ} / \mathrm{s}$ (abscissa) and $40^{\circ} / \mathrm{s}$ (ordinate) for a $2^{\circ}$ overall target displacement (A: $20^{\circ} / \mathrm{s}$ during $100 \mathrm{~ms}$ vs $40^{\circ} / \mathrm{s}$ during $50 \mathrm{~ms}$ ) and $4^{\circ}$ overall target displacement (B: $20 \%$ s during $200 \mathrm{~ms}$ vs $40 \%$ s during $100 \mathrm{~ms}$ ). Data are shown for each monkey (Monkey G: Monkey A: $\square$; Monkey M: ) and each quadrant. Bottom, Difference in horizontal final positions as a function of difference of latency for saccades made in response to the $2^{\circ}\left(\boldsymbol{C}: 50 \mathrm{~ms}\right.$ at $40^{\circ} / \mathrm{s} \mathrm{vs} 100 \mathrm{~ms}$ at $\left.20^{\circ} / \mathrm{s}\right)$ and $4^{\circ}\left(\mathbf{D}: 100 \mathrm{~ms}\right.$ at $40^{\circ} / \mathrm{s} \mathrm{vs} 200 \mathrm{~ms}$ at $\left.20^{\circ} / \mathrm{s}\right)$ target displacements. Each data point corresponds to the median value of horizontal final positions.

the Monkey A (Fig. 2B: $5.4 \pm 2.0^{\circ}$ vs $4.1 \pm 1.1^{\circ}$; Mann-Whitney nonparametric test, $p<0.001)$ and Monkey M (Fig. 2C: $5.8 \pm$ $1.7^{\circ}$ vs $\left.4.9 \pm 1.1^{\circ} ; p<0.001\right)$. In Monkey $\mathrm{G}$, there is no significant difference (Fig. $2 A: 3.8 \pm 2.0^{\circ}$ vs $3.9 \pm 1.4^{\circ} ; p>0.05$ ). Third, the saccades toward the moving target land on positions that are located beyond the endpoints of saccades toward a static target $\left(1.4 \pm 0.9^{\circ}, 2.6 \pm 0.4^{\circ}\right.$ and $2.4 \pm 0.4^{\circ}$ in Monkeys G, A, and M, respectively; $p<0.001)$. Comparable observations are made in the saccades elicited by a $4^{\circ}$ target displacement: the horizontal final positions are more eccentric when the target moves at $40 \%$ for $100 \mathrm{~ms}$ than when it moves at $20^{\circ}$ s for $200 \mathrm{~ms}$ in Monkey G (Fig. $2 D$ : $6.1 \pm 1.6^{\circ}$ vs $4.9 \pm 1.8^{\circ} ; p<0.001$ ), in Monkey A (Fig. $2 E: 6.6 \pm 1.6^{\circ}$ vs $5.0 \pm 1.5^{\circ} ; p<0.001$ ) and in Monkey M (Fig. $2 F$ : $7.9 \pm 1.3^{\circ}$ vs $\left.5.1 \pm 1.4^{\circ} ; p<0.001\right)$. The saccades to the moving target also land on positions that are located horizontally beyond the endpoints of saccades toward a static target presented at the location where the moving target disappeared $\left(3.7 \pm 0.8^{\circ}, 4.8 \pm\right.$ $0.6^{\circ}$ and $3.8 \pm 0.7^{\circ}$ in Monkeys $\mathrm{G}, \mathrm{A}$, and $\mathrm{M}$, respectively; $p<$ $0.001)$.

The generalization of these observations to the other quadrants and monkeys can be seen in Figure 3. The median values of horizontal final positions are plotted for saccades made in re- sponse to identical displacements of the target (graph A: $2^{\circ}$; graph B: $4^{\circ}$ ) but with different speeds (abscissa: $20^{\circ} / \mathrm{s}$; ordinate: $40 \%$ s). Although the duration of target visibility is half as long, the final positions are more deviated horizontally when the saccades are made to the faster target $(40 \%)$ than to the slower one $(20 \%)$. The paired comparison of median values reveals statistically significant differences when the horizontal amplitude of the target displacement is $2^{\circ}$ (Fig. $3 A$ : average difference $\left.=0.6 \pm 0.9^{\circ} ; p<0.05\right)$ as well as $4^{\circ}$ (Fig. $3 B: 1.6 \pm 0.9^{\circ} ; p<0.05$ ). The more eccentric final positions with the faster target are not due to longer latencies of saccades. When we consider the saccades made in response to the $2^{\circ}$ horizontal target displacement, the paired comparison of median latencies does not show any significant difference between the faster $(40 \% \mathrm{~s})$ and the slower $(20 \% \mathrm{~s})$ target (average difference of median latencies $=-2 \pm 9 \mathrm{~ms}$; Wilcoxon nonparametric test: $p>0.05)$. A small but significant latency increase $(6 \pm 9 \mathrm{~ms} ; p<$ $0.05)$ is observed in the saccades made to the $4^{\circ}$ horizontal target displacement, but this difference is negligible because it corresponds to an additional target displacement of $3 \%\left(0.12^{\circ}\right)$. Furthermore, there is no statistically significant correlation between the differences of latency $(x)$ and the differences of horizontal final positions $(y)$ (nonparametric Spearman correlation coefficient $R(x, y)=-0.14$ for the $2^{\circ}$ target displacement and $R(x, y)=0.21$ for the $4^{\circ}$ target displacement, $p>0.05$; Fig. $3 C, D)$. Concerning the comparison with the endpoints of saccades toward a static target, the paired comparison across all quadrants and monkeys reveals more eccentric horizontal final positions for saccades toward a target moving over $2^{\circ}$ (during $50 \mathrm{~ms}$ at $40 \%$ s or during $100 \mathrm{~ms}$ at $20 \% \mathrm{~s}$ ) than for saccades toward a $2^{\circ}$ horizontally eccentric static target (average differences $=$ $1.7 \pm 1.9^{\circ}$ and $1.1 \pm 1.2^{\circ}$ respectively; $p<0.05$ ). In summary, despite identical overall target displacements and shorter duration of target visibility, the saccades toward the faster target land beyond the endpoint of saccades toward the slower target.

To further explore this influence of target speed, we tested saccades made in response to target motions that were identical in duration and displacement but had different rates of change of speed. Figure 4 shows the time course of the horizontal and vertical components of oblique saccades toward a target that moves in the upper right quadrant. In the top row (accelerating target), the target speed either increases linearly from 0 to $80 \%$ during $100 \mathrm{~ms}$ (Fig. $4 A$, average speed $=40 \%$ ), from 0 to $40 \%$ during $200 \mathrm{~ms}$ (Fig. $4 B$, average speed $=20 \%$ ) or increases linearly from 0 to $40 \%$ s during the first $100 \mathrm{~ms}$ and again during the next $100 \mathrm{~ms}$ (Fig. $4 \mathrm{C}$; average speed $=20 \%$ ). In the bottom row (decelerating target), the target speed decreases linearly from 80 to $0 \%$ during $100 \mathrm{~ms}$ (Fig. $4 D$; average speed $=40 \%$ ), from 40 to $0 \%$ during $200 \mathrm{~ms}$ (Fig. $4 E$; average speed $=20^{\circ} / \mathrm{s}$ ), or decreases linearly 
from 40 to $0 \%$ s during $100 \mathrm{~ms}$ and again during the following $100 \mathrm{~ms}$ (Fig. 4F; average speed $=20 \%$ s). The comparison between the leftmost and middle graphs (graph B vs graph A and graph E vs graph D) illustrates again that the horizontal amplitude is larger for saccades directed toward the faster target, even though the motion duration is shorter and the target displacements identical. When the target displacements and motion durations are identical, the horizontal amplitude of saccades is larger when they are directed toward the decelerating target than toward the accelerating one (compare graph $\mathrm{D}$ vs graph A and graph E vs graph B). The fact that the target locations are at more eccentric locations early in the motion in the decelerating speed condition is not sufficient to explain this difference because the saccades do not land toward these early locations. Moreover, we will see later how the saccades toward an accelerating target can also land beyond its last visible position. Similarly, the horizontal landing positions are slightly less eccentric for the saccades toward the target that discontinuously decelerates than for the saccades toward the target that continuously decelerates during the same time interval (compare graph $\mathrm{E}$ vs graph $\mathrm{F}$ ).

Figure 5 shows the distribution of horizontal final positions for oblique saccades made in response to a target displacement of $4^{\circ}$ during $200 \mathrm{~ms}$ in the upper right quadrant. As in saccades toward a target moving with a constant speed, the final position values of saccades toward a decelerating target are symmetrically distributed even though the target speed itself is also temporally asymmetric. This symmetry is absent when we consider saccades toward an accelerating target; the distribution is biased toward smaller position values. The horizontal final positions are significantly less eccentric when the target accelerates than when it decelerates in Monkey G (Fig. $5 A$ : $3.2 \pm 2.9^{\circ}$ vs $6.2 \pm 1.5^{\circ} ; p<0.001$ ), in Monkey A (Fig. $5 B: 2.9 \pm 1.9^{\circ}$ vs $5.6 \pm 1.0^{\circ} ; p<0.001$ ), and in Monkey M (Fig. $5 C: 3.4 \pm 1.7^{\circ}$ vs $\left.7.4 \pm 1.0^{\circ} ; p<0.001\right)$. Similarly, the horizontal final positions of saccades to the accelerating target are less eccentric than the endpoints of saccades toward a target moving with a constant speed in Monkey G (Fig. $5 A$ : $3.2 \pm 2.9^{\circ}$ vs $4.9 \pm 1.8^{\circ} ; p<$ 0.005 ), in Monkey A (Fig. $5 B: 2.9 \pm 1.9^{\circ}$ vs $4.9 \pm 1.5^{\circ} ; p<0.001$ ), and in Monkey M (Fig. $5 C$ : $3.4 \pm 1.7^{\circ}$ vs $5.1 \pm 1.4^{\circ} ; p<0.001$ ).

This influence of the target speed is further documented for all quadrants and monkeys in Figure 6. The median values of horizontal final positions of saccades toward the decelerating target (ordinate) are plotted against those of saccades toward the accelerating target (abscissa). Therefore, although the duration and amplitude of the target motion are identical, the positions are more deviated when the target speed linearly decreases from 40 to $0 \%$ s than when it linearly increases from 0 to $40 \%$ during $100 \mathrm{~ms}$ (Fig. 6A). The difference is small (average difference $=0.3 \pm 0.4^{\circ}$ corresponding to $15 \%$ of the target displacement) but statistically significant (Wilcoxon text; $p<$ 0.05). For a target displacement of $4^{\circ}$ during $200 \mathrm{~ms}$ (Fig. $6 B$ ), the difference in horizontal eye deviation is larger (average difference $=$ $\left.2.4 \pm 0.6^{\circ} ; p<0.05\right)$. The difference of horizontal final positions

\section{Accelerating target}

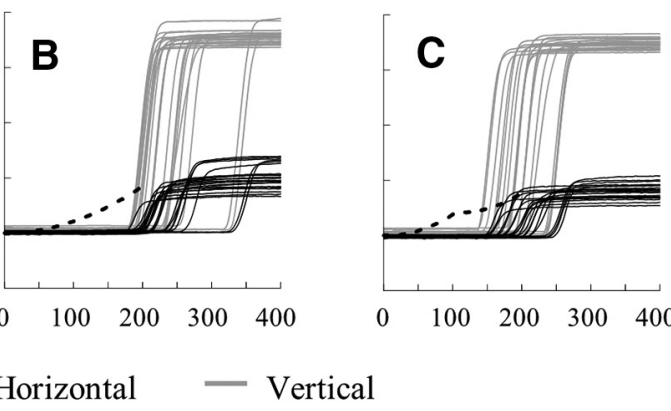

\section{Decelerating target}
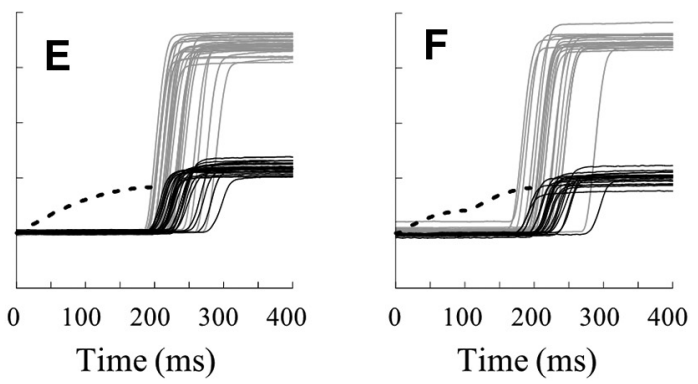

Figure 4. Time course of saccades toward an accelerating or decelerating target. In the top row, the saccades (horizontal . In the right column, the target speed changes linearly from 0 to $40 \% \mathrm{~s}(\boldsymbol{C})$ or from 40 to $0 \% \mathrm{~s}(\boldsymbol{F})$ during the first 100 ms and again during the next $100 \mathrm{~ms}$. The time course of target position is illustrated by the dotted black line. The selected saccades

between saccades toward an accelerating versus a decelerating target does not reach statistical significance (average difference $=0.4 \pm$ $\left.1.2^{\circ} ; p>0.05\right)$ when the $4^{\circ}$ target displacement occurs during a short interval (100 ms); that is, when the change in target speed amounts to $80 \%$ (examples shown in Fig. 4). However, when the same change in target speed occurs during a longer interval ( $200 \mathrm{~ms})$, the horizontal final positions are again more deviated when the target decelerates than when it accelerates (Fig. $6 C$; average difference $=3.2 \pm$ $1.5^{\circ} ; p<0.001$ ). These differences cannot be due to longer saccade latencies when the target decelerates versus when it accelerates. If any, the differences in latency between the two groups of saccades are indeed very small, whether the target speed changes happens during $100 \mathrm{~ms}$ [Monkey G: $222 \pm 36(n=313)$ vs $222 \pm 36 \mathrm{~ms}(n=165)$; Monkey A: $174 \pm 44(n=448)$ vs $178 \pm 36 \mathrm{~ms}(n=528)$; Monkey M: $188 \pm 31(n=128)$ vs $176 \pm 30 \mathrm{~ms}(n=135)$; values for the accelerating and decelerating targets, respectively] or during $200 \mathrm{~ms}$ [Monkey G: $214 \pm 26(n=94)$ vs $212 \pm 30(n=577)$ ms; Monkey A: $158 \pm 52(n=493)$ vs $190 \pm 48 \mathrm{~ms}(n=411)$; Monkey M: $182 \pm$ $32(n=98)$ vs $200 \pm 34 \mathrm{~ms}(n=122)]$. Similarly, the differences in latency are small when the target speed changes between 0 and $80 \%$ during $200 \mathrm{~ms}$ [Monkey G: $208 \pm 26(n=171)$ vs $216 \pm 30 \mathrm{~ms}(n=$ 152); Monkey A: $160 \pm 44(n=398)$ vs $198 \pm 66 \mathrm{~ms}(n=417)$; Monkey M: $205 \pm 68(n=104)$ vs $192 \pm 24 \mathrm{~ms}(n=118)]$. Furthermore, there is no statistically significant correlation between the differences of latency $(x)$ and the differences of horizontal final positions $(y)$ between saccades toward a decelerating versus an accelerating target [Spearman coefficients $R(x, y)=-0.30$ for the $2^{\circ}$ target displacement (graph D), $R(x, y)=0.51$ for the $4^{\circ}$ target displacement (graph E) and $R(x, y)=0.64$ for the $8^{\circ}$ target displacement (graph F); $p>0.05$ ]. In summary, although the target displacements 

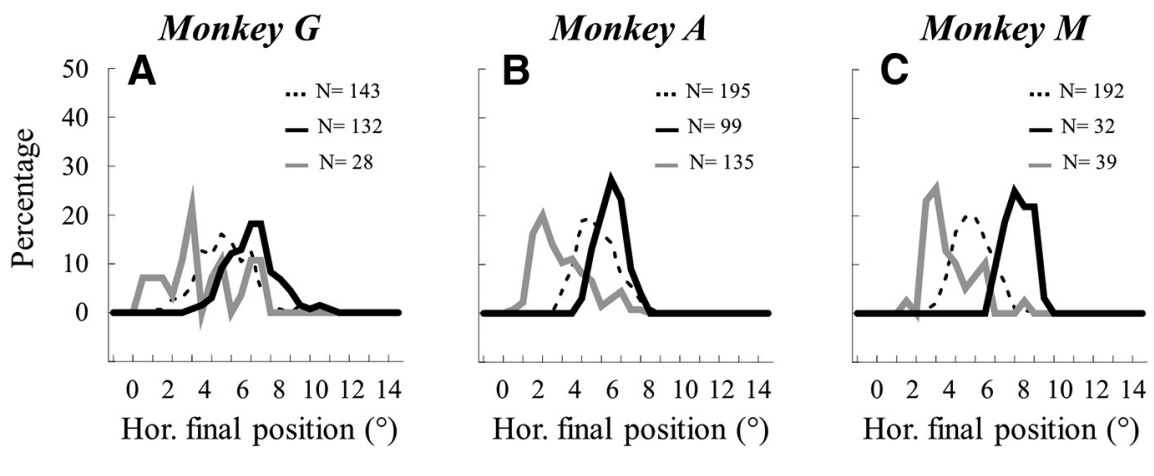

.... Constant speed - Decreasing speed - Increasing speed

Figure 5. Distribution of the horizontal final positions of saccades to transient targets moving with different speed profile. For each monkey ( $\boldsymbol{A}$, Monkey $\mathrm{G} ; \boldsymbol{B}$, Monkey $\mathrm{A} ; \boldsymbol{C}$, Monkey $\mathrm{M})$, the distribution of the horizontal final positions is shown for all saccades made in response to a target that moves in the upper right quadrant during $200 \mathrm{~ms}$ with a constant speed ( $20 \% \mathrm{~s}$, dashed line), with a speed increasing from 0 to $40 \%$ (solid gray line), or with a speed decreasing from 40 to $0 \% \mathrm{~s}$ (solid black line).
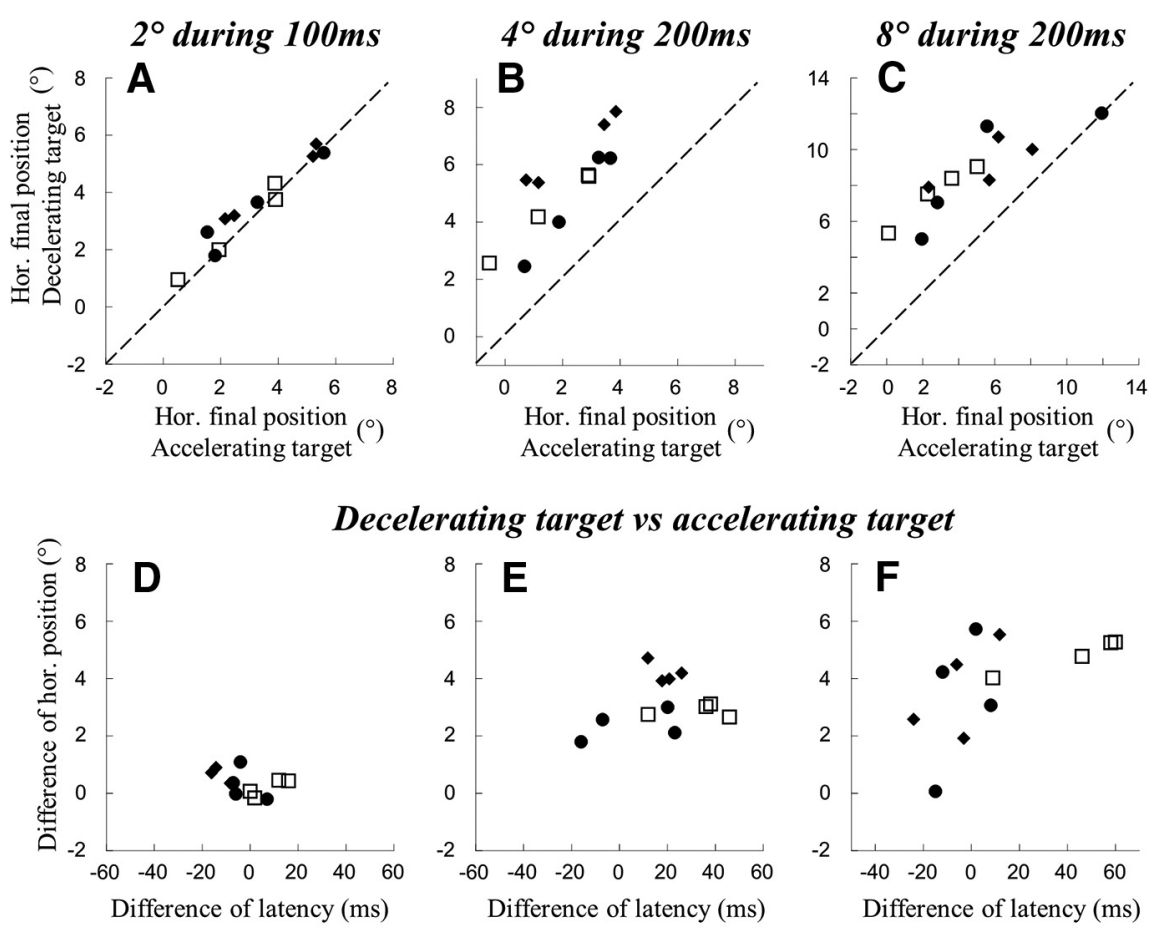

\section{- Monkey G $\square$ Monkey A • Monkey M}

Figure 6. Influence of target speed profile on the saccade endpoint and latency. Top, Horizontal final position of saccades made in response to identical target motion duration and displacement but different speed profile. The final positions of saccades to a decelerating target are plotted against the final positions of saccades to an accelerating target. Bottom, Difference of horizontal final position against difference of latency. The target moved for $2^{\circ}$ during $100 \mathrm{~ms}(\boldsymbol{A}, \boldsymbol{D}), 4^{\circ}$ during $200 \mathrm{~ms}(\boldsymbol{B}, \boldsymbol{E})$, or $8^{\circ}$ during $200 \mathrm{~ms}(\boldsymbol{C}, \boldsymbol{F})$. Median values and their difference are shown for all quadrants and monkeys (Monkey G: Monkey A: $\square$; Monkey M: $\diamond$ ).

and durations are identical, the saccades have smaller horizontal amplitude when they are made in response to an accelerating target than to a decelerating target. The rate of change in speed matters in the transformation of the retinal streak of activity into saccadic oculomotor commands.

The different endpoints between saccades to accelerating and decelerating targets could be due to different neuronal dynamics. In the gradual specification of the amplitude of saccades (Sparks et al., 1987), the target-motion-related signals may not have the same weight depending upon their timing relative to the target appearance. Early signals may be more prone to influence the saccade end- points than later signals for the mere reason that they are the first to reach the saccaderelated premotor centers in the brainstem. We further tested this possibility by comparing saccades toward a target that accelerated from 0 to $40 \%$ during different intervals. If the early signals are more influential than the later signals, saccades toward a target that accelerates from 0 to $40 \%$ s during a short interval $(100 \mathrm{~ms})$ should land more eccentrically than saccades toward a target that accelerates similarly but during a longer interval $(200 \mathrm{~ms})$ even though the horizontal target displacement is doubled in the second case. Our results show that it is indeed the case. When we consider, for example, the saccades toward a target moving in the upper right visual field (Figs. 2, 5), the horizontal final positions are more eccentric when the target accelerates during $100 \mathrm{~ms}$ than during $200 \mathrm{~ms}$ in Monkey G [5.6 \pm $2.2^{\circ}(n=65)$ vs $3.2 \pm 2.9^{\circ}(n=28) ; p<$ 0.001 ], in Monkey A [middle: $3.9 \pm 1.0^{\circ}$ $(n=112)$ vs $2.9 \pm 1.9^{\circ}(n=135) ; p<$ $0.001]$, and in Monkey M $\left[5.2 \pm 1.2^{\circ}(n=\right.$ $37)$ vs $\left.3.4 \pm 1.7^{\circ}(n=39) ; p<0.001\right]$ despite a halved displacement of the target. This result is documented for all quadrants and monkeys in Figure 7A. The horizontal final positions (median values) of saccades toward a target accelerating from 0 to $40 \%$ during $200 \mathrm{~ms}$ (ordinate) are plotted against those toward a target accelerating during $100 \mathrm{~ms}$ (abscissa). The fact that the majority of data points are situated below the diagonal dashed line (unity slope) illustrates that saccades toward a target that accelerates during a short interval (from 0 to $40 \%$ s during $100 \mathrm{~ms}$ ) land more eccentrically than saccades toward a target that accelerates during longer intervals (from 0 to $40 \%$ s during $200 \mathrm{~ms}$ ) even though the horizontal target displacement is doubled. The paired comparison of the two groups of saccades reveals that this difference $\left(1.0 \pm 0.7^{\circ}\right)$ is statistically significant $(p<0.005)$. In summary, the target-motion-related signals have different weight depending upon their timing relative to the target onset: early signals are more prone to influence the endpoint of saccades than later signals.

This result must not be taken as evidence that the target-motion-related signals would be "sampled" during the first $100 \mathrm{~ms}$ period and that the visuo-oculomotor system would be refractory to subsequent visual input before the saccade is launched. Indeed, when we consider the saccades toward a target moving in the upper right visual field (as above) and compare the horizontal final eye positions of saccades directed toward a target that decelerates from 40 to $0 \%$, the horizontal final positions are less eccentric when the deceleration lasts 100 $\mathrm{ms}$ than when it lasts $200 \mathrm{~ms}$ in Monkey G [5.4 $\pm 1.6^{\circ}(42)$ vs $\left.6.2 \pm 1.5^{\circ}(132) ; p<0.001\right]$ and in Monkey A $\left[3.7 \pm 0.8^{\circ}(144)\right.$ vs $\left.5.6 \pm 1.0^{\circ}(99) ; p<0.001\right]$, but not in Monkey M $\left[5.2 \pm 0.8^{\circ}(37)\right.$ 
Accelerating target Decelerating target $100 \mathrm{~ms}$ versus $200 \mathrm{~ms}$
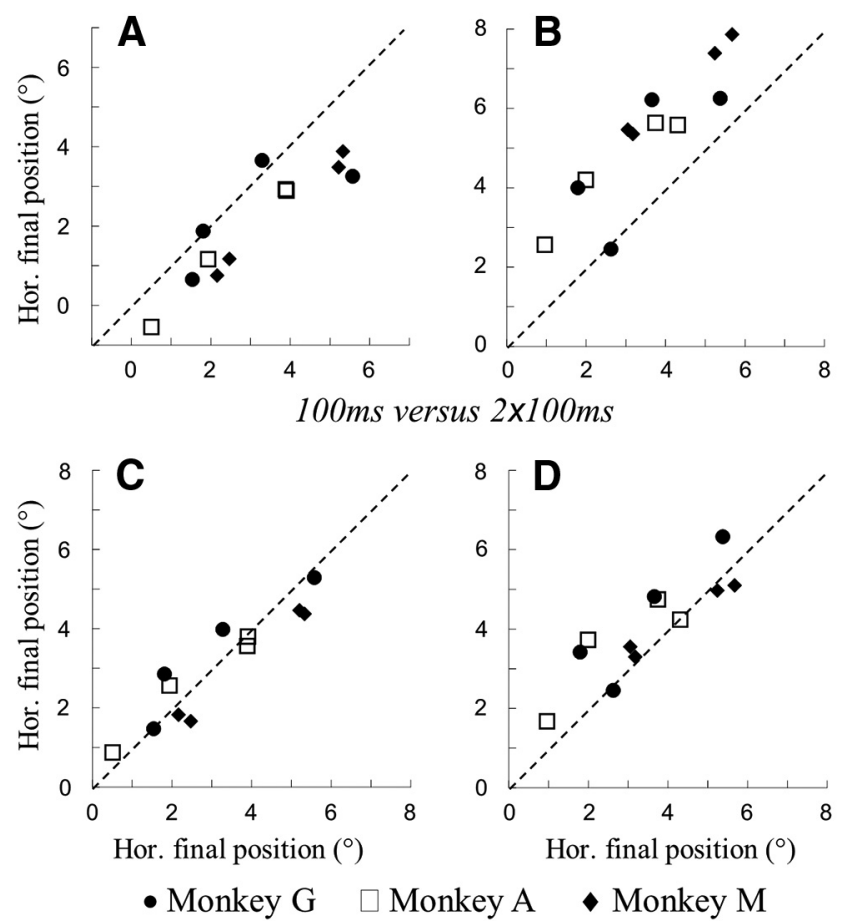

Figure 7. Influence of target duration and speed profile. Horizontal final eye position of saccades toward a target that moves from 0 to $40 \%$ (left) or from 40 to $0 \%$ (right) with different durations. $\boldsymbol{A}, \boldsymbol{B}, 100 \mathrm{~ms}$ (abscissa) versus $200 \mathrm{~ms}$ (ordinate). C, D, $100 \mathrm{~ms}$ (abscissa) versus two times $100 \mathrm{~ms}$ (ordinate) for all quadrants and monkeys (Monkey G: O; Monkey A: $\square$; Monkey M: $\bullet$ ).

vs $\left.7.4 \pm 1.0^{\circ}(32) ; p>0.05\right]$. Figure $7 B$ further documents this result for all quadrants and all monkeys. The horizontal final positions (median values) of saccades toward a target decelerating from 40 to $0 \%$ during $200 \mathrm{~ms}$ (ordinate) are plotted against those to a target decelerating during $100 \mathrm{~ms}$ (abscissa). The majority of data points are situated above the diagonal, indicating that saccades toward a target that decelerates during a longer interval (from 40 to $0 \% \mathrm{~s}$ during $200 \mathrm{~ms}$ ) land more eccentrically than saccades toward a target that decelerates during a shorter interval $(100 \mathrm{~ms})$. The paired comparison of the two groups of saccades reveals that this difference $\left(1.0 \pm 1.0^{\circ}\right)$ is statistically significant $(p<0.05)$. Furthermore, when the horizontal final position is compared between saccades toward a target that decelerates from 40 to $0 \%$ during $100 \mathrm{~ms}$ and saccades toward a target that decelerates two times from 40 to $0 \%$ s (Fig. $4 E$, first deceleration during the first $100 \mathrm{~ms}$ followed by a second deceleration during the next $100 \mathrm{~ms}$ ), most median values are situated above the unity slope (Fig. $7 D$ ) and the paired comparison reveals that this difference $\left(0.5 \pm 0.7^{\circ}\right)$ is statistically significant $(p<$ 0.05 ). Finally, when, instead of decelerating, the target accelerates, the horizontal final positions are not significantly different between saccades directed toward a target that accelerates twice and those toward a target that accelerates only during $100 \mathrm{~ms}$ (Fig. 7C; average difference $=0.3 \pm 0.5^{\circ}$ ).

We have seen that the saccades made in response to a transient moving target overshoot the location where the target disappeared with a magnitude that depends upon the target speed. Moreover, the endpoints are horizontally more scattered than the landing positions of saccades toward a static target (Fig. 2). Figure 8 shows that this variability is related to the response time (i.e., the time interval from the target motion onset to the saccade end) and that this relation depends upon the rate of change in target speed. The positions are plotted as a function of the response time rather than the latency because there is no evidence that the target-related signals (those acquired before the saccade onset) stop feeding the saccade-related premotor neurons when they emit their burst. When the target moves in the upper right visual field with a speed that increases from 0 to $40 \%$ during $200 \mathrm{~ms}$ (Fig. $8 A, D, G$, left), the horizontal position of saccade endpoints increases linearly with the response time for each monkey. The later the time of saccade landing, the more eccentric the horizontal position of its endpoint. The saccades with the latest landing times overshoot the location where the target disappeared (position values larger than $4^{\circ}$ ), whereas those with the earliest landing times fall short of the current target location (position values smaller than $4^{\circ}$ ). It is noticeable that the slopes regressing the relations between the landing positions and times (Fig. 8 A: 58\% $/$ s; Fig. $8 D: 30 \%$ s; Fig. 8 G: $36^{\circ} / \mathrm{s}$ ) exceed the average speed of the target $\left(20^{\circ} / \mathrm{s}\right)$. Different slope values are observed between the saccades made toward the different quadrants. In Monkey G, the slope is $39^{\circ} / \mathrm{s}$ for the lower right quadrant, $29 \%$ and $39 \%$ for the upper and lower left quadrant. In Monkey A, the slope is $21 \%$ s for the lower right quadrant, $22 \%$ and $23 \%$ for the upper and lower left quadrant. In Monkey $\mathrm{M}$, the slope is $48 \%$ s for the lower right quadrant, $30 \%$ and $26 \%$ for the upper and lower left quadrant. This variability is related to the landing time of saccades. Indeed, the slopes $(x)$ are positively correlated with the average landing time of saccades $(y)$ (Spearman correlation; $R(x, y)=0.81$, $p<0.05)$. When the target moves in the upper right visual field with a constant speed $\left(20^{\circ} \mathrm{s}\right.$ during $200 \mathrm{~ms}$; middle col$\mathrm{umn}$ ), the horizontal position of saccade endpoints also increases linearly with time. Most saccades overshoot the location where the target has disappeared (position values larger than $4^{\circ}$ ). The slopes regressing the relations between the landing positions and times are smaller than the values measured above on saccades to the accelerating target (Fig. 8B: $31 \%$ s; Fig. 8 E: $13 \%$ s; Fig. $8 H: 23 \%$ s). When we consider all quadrants, the slope values range from 13 to $20 \%$ in Monkey A, from 6 to $31 \%$ in Monkey G, and from 18 to $24^{\circ} \%$ in Monkey M. Finally, when we consider the saccades in response to the decelerating target (speed decreases from 40 to $0 \% \mathrm{~s}$ during $200 \mathrm{~ms}$ in the upper right quadrant; Fig. $8 C, F, I$ ), all saccades overshoot the location where the target has disappeared (position values larger than $4^{\circ}$ ). The relation between the landing positions and times is also much weaker (lower slope and $R^{2}$ values). When we consider all quadrants, the regression slopes range from 3 to $9 \%$ in Monkey A, from 1 to $24 \%$ in Monkey G, and from 5 to $15^{\circ}$ s in Monkey M. In summary, the landing positions of saccades are correlated with their landing times in a manner that is sensitive to the rate of change of target speed: the faster the target before the time of saccade end, the stronger the correlation.

Although the medium in which the neural activities propagate is different (neither homogeneous nor isotropic) from the arithmetical fabric in which they are represented, and although the physics of the propagation of visual signals remains largely unknown, an hypothetical extrapolation error (eye position at saccade end relative to target location at saccade end) was calculated for if the target had continued to move along its predefined trajectory. This numerical value is plotted in Figure 9 as a func- 

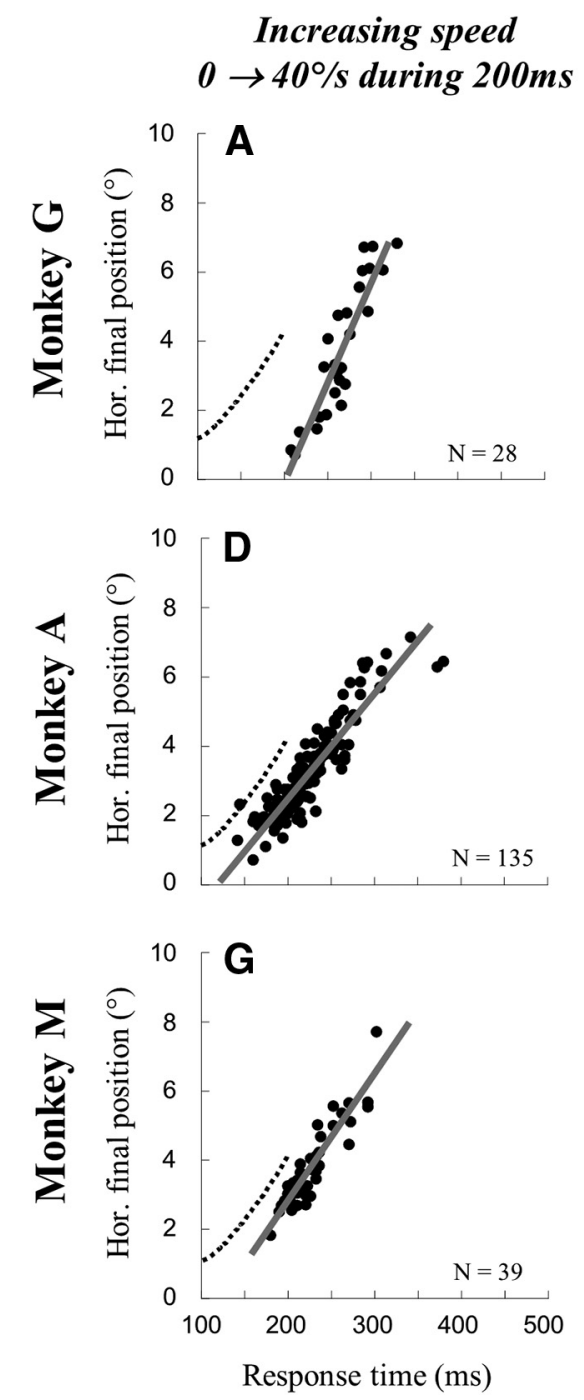
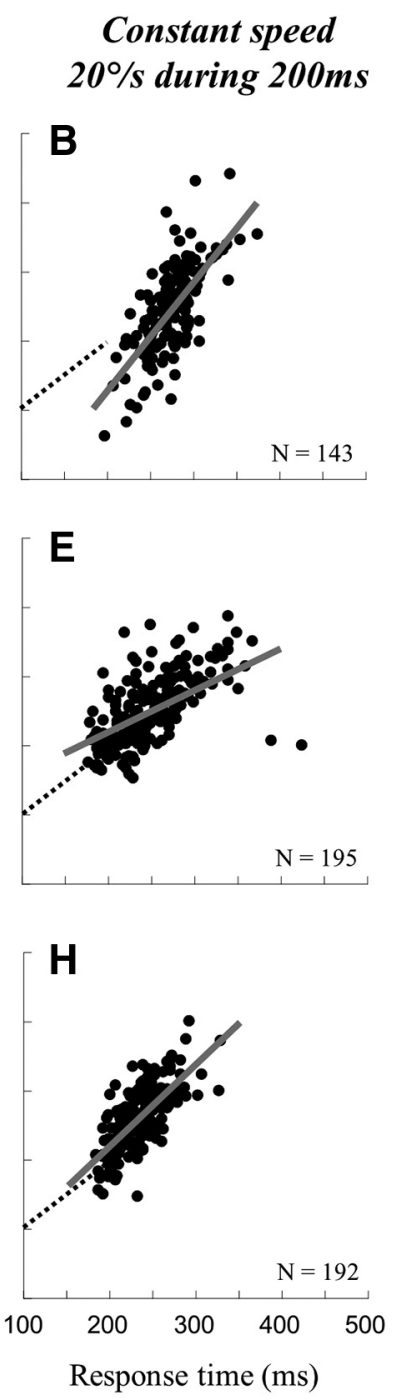

Decreasing speed $40 \rightarrow 0 \%$ during $200 \mathrm{~ms}$
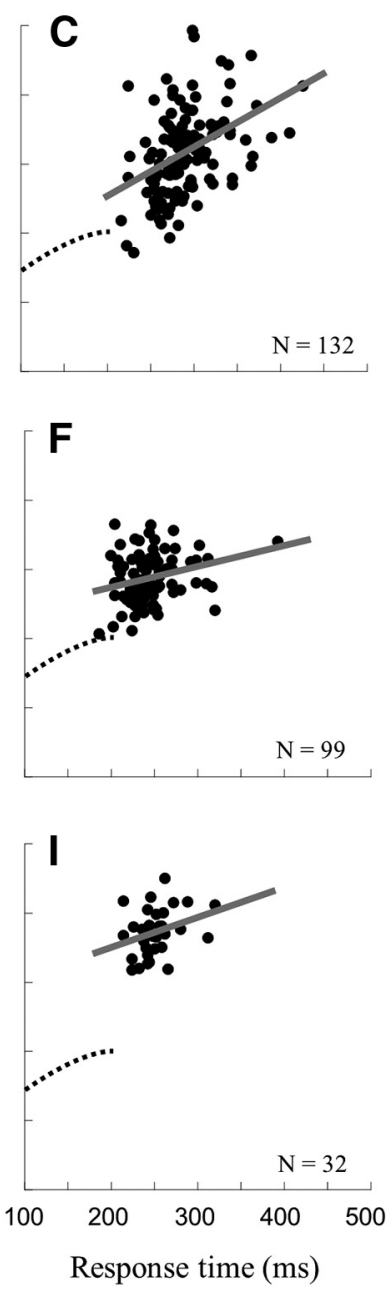

Figure 8. The extrapolation mimics the final target speed. For each monkey (Monkey G: top; Monkey A: middle; Monkey M: bottom), the horizontal final eye positions are plotted as a function of the response time (landing time) of saccades made in response to a target moving in the upper right visual quadrant with an increasing speed (from 0 to $40^{\circ} / \mathrm{s} ; \boldsymbol{A}, \boldsymbol{D}, \boldsymbol{G}$ ), a constant speed ( $20^{\circ} / \mathrm{S}$, $\boldsymbol{B}, \boldsymbol{E}, \boldsymbol{H}$ ), or a decreasing speed (from 40 to $0 \%, \boldsymbol{C}, \boldsymbol{F}, \boldsymbol{I}$ ) during $200 \mathrm{~ms}$. The target position during the last $100 \mathrm{~ms}$ is illustrated by the dotted black line.

tion of the response time for the same data as in Figure 8. Therefore, one can better appreciate the undershoot (negative error values) of saccades toward the accelerating target (Fig. 9, left column) and the overshoot (positive error values) of saccades toward the decelerating target (Fig. 9, right column). The middle column also shows how this numerical value fluctuates around zero for saccades toward the target that moved with the constant speed.

\section{Discussion}

In this work, we investigated how visual signals yielded by a transient moving target are transformed into commands for generating a saccade. At the input side, the target motion evokes a streak of retinal activity, whereas at the output, a phasic change in the contraction of extraocular muscles quickly reorients the gaze. Our results show that the saccades rarely direct gaze toward the locations traveled by the target; most saccades land beyond the last visible location. Therefore, on the basis of antecedent signals, the visuo-saccadic system extrapolates a landing position. This extrapolation does not involve a process that uniformly integrates speed signals or converts successive position signals into a vectorial command encoding a target displacement. For identical overall (not instantaneous) target displacements on the visual display, the landing position is more eccentric with faster targets (Figs. $3 A, B, 6 A-C$ ). The landing depends more upon the target speed than the duration or amplitude of the target displacement. Furthermore, depending upon their timing relative to the target onset, the motion-related signals do not have the same weight. Early signals are more influential than later signals in the specification of saccade amplitude, likely because they are the first to reach the saccade-related premotor centers. The saccade endpoints are indeed more eccentric when the speed is faster at target onset (Figs. 6A-C, 7A). This dominance of early signals does not mean that later signals have no influence. On the contrary, the latter also participate in the specification of saccade amplitude (Figs. $7 B-D, 8$ ). Below, we discuss the "predictive" properties of the visuo-saccadic system and the "here-andnow" hypothesis (Fleuriet and Goffart, 2012) before considering the nature of the location where the saccades land in response to a moving target.

Do saccades aim at the future position of a moving target? The idea was proposed that the saccades toward a moving target reflect the ability to predict the future target location. Based on 


\section{Increasing speed $0 \rightarrow 40 \%$ during $200 \mathrm{~ms}$}
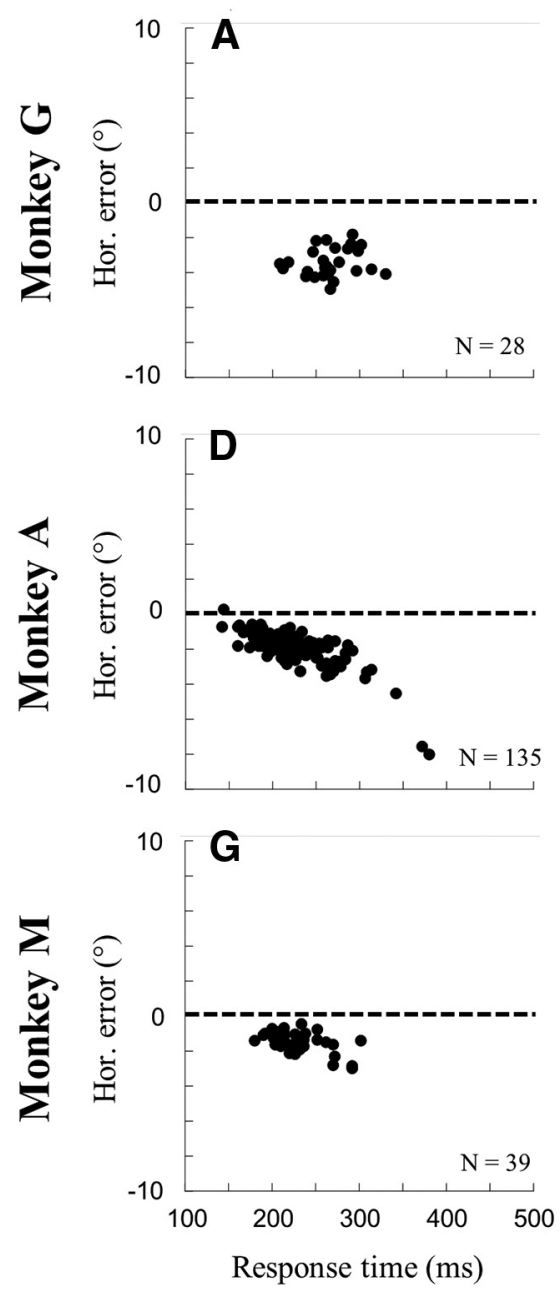
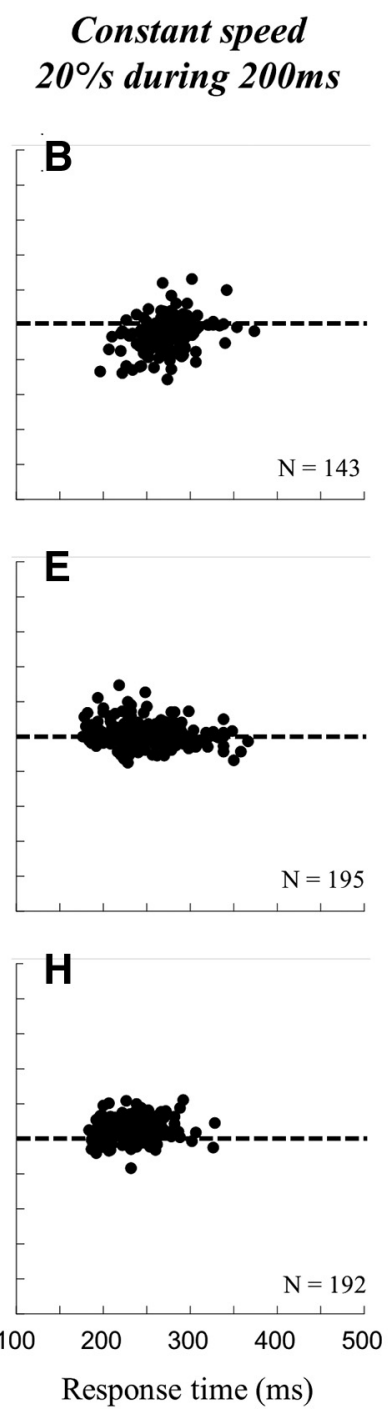

Decreasing speed $40 \rightarrow 0 \%$ during $200 \mathrm{~ms}$
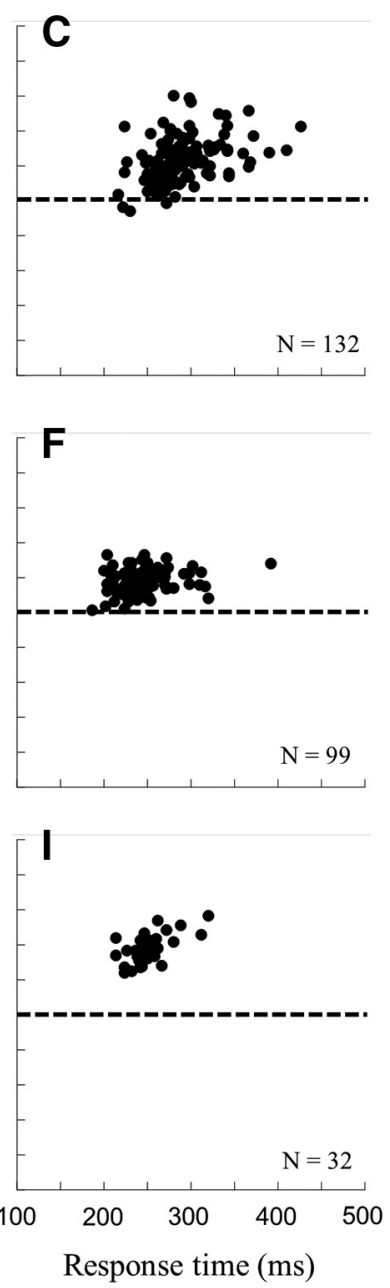

Figure 9. Hypothetical extrapolation error. For the same data as plotted in Figure 8 (Monkey G: top; Monkey A: middle; Monkey M: bottom), the hypothetical horizontal errors are plotted as a function of the response time (landing time) for all saccades made in response to a target moving in the upper right visual quadrant with an increasing speed (from 0 to $\left.40^{\circ} / s ; \boldsymbol{A}, \boldsymbol{D}, \mathbf{G}\right)$, a constant speed $(20 \%, \boldsymbol{B}, \boldsymbol{E}, \boldsymbol{H})$, or a decreasing speed (from 40 to $0 \% \mathrm{~s}, \boldsymbol{C}, \boldsymbol{F}, \boldsymbol{I})$ during $200 \mathrm{~ms}$. The numerical value of error is the eye position at saccade end relative to target location at saccade end had the target continued to move along its predefined trajectory (see the text for detailed interpretations).

observations made in the cat, Klam et al. (2001) suggested that "in programming interceptive saccades, target motion is used to predict the future target position so as to assure a spatial lead of the gaze at the saccade end, instead of attempting a precise capture of the target." Somehow, the visuo-oculomotor system would estimate "the time remaining until the collision of the target with the line of sight" (Klam et al., 2001) or "the time at which the eye trajectory will cross the target" (de Brouwer et al., 2002, a study with human subjects).

This protentional view is problematic for two reasons. First, a freely moving object can occupy a large number of locations. Its upcoming position depends upon so many factors (e.g., the direction of its motion relative to the observer, its depth, its speed and acceleration, its lifetime, the cluttering and the regularities of its environment, etc.) that considering that the brain activity could encode its future position implies that it is "cognizant" of all these factors some time before the interception. A more fundamental problem is hidden behind this ability to "predict the future position," which is to understand how the trajectories are memorized and retrieved (Dudai, 2009) and how they guide the ongoing action (Goffart et al.,
2014). Second, most observations in the monkey show that the interceptive saccades do not orient the foveae toward any (undefined) "future" location where the gaze would be maintained, waiting for the target to enter within the foveal field and initiate its pursuit (Lisberger, 1998). Only during the Rashbass paradigm does the target move toward the foveal field while the gaze remains stationary (Rashbass, 1961). However, this laboratory condition is extraordinary because it requires that the target starts moving from a restricted zone of the visual field and toward the foveal field. In fact, all data show that the interceptive saccades either fall short or land approximately at the location where the target is at the time of saccade landing (Robinson, 1965; Fuchs, 1967; Barmack, 1970; Keller and Johnsen, 1990; Cassanello et al., 2008; Fleuriet et al., 2011) even when their trajectory is perturbed (Fleuriet and Goffart, 2012). When the spatiotemporal coincidence is not reached (undershoot), correction (catch-up) saccades are made to bring the target image back onto the foveae. Therefore, rather than the future position of a moving target, the brain activity encodes at best its expected position, here-and-now (Goffart et al., 2014), on the basis of antecedent 
visual signals and adaptive signals acquired during previous training experiences.

\section{Comments on the "here-and-now" hypothesis}

Fleuriet and Goffart (2012) hypothesized that the gaze trajectory is guided by an estimate of the expected and current spatiotemporal position of the target. In their perturbation experiments, the monkeys were trained to track a target moving along a horizontal path with a constant speed. There was no uncertainty about the target motion direction (always horizontal) and speed (constant). The target appeared either in the upper or lower visual field and moved either rightward or leftward. After a short displacement, it was briefly blanked during its course toward the edges of the visual display. Therefore, the motion signals that preceded the blank fully determined the upcoming target path. There was no uncertainty about whether the target would reappear and keep moving along the same path; that is, that it would not move backward or change its direction during the blank. Using a brief microstimulation in the deep SC at the onset of the blank interval, changes of saccade trajectory were elicited experimentally and, despite stimulation-induced changes in eye position and delays, correction saccades were generated, sometimes after an intersaccadic pause. These saccades did not bring gaze toward any future position of the target; they landed next to the location where unperturbed saccades would have landed at about the same time. The present work complements this perturbation study by showing that saccades to a transient moving target land beyond the location where the target disappeared. When the target moves at constant speed, the saccades land approximately where the target would be if it were still moving during the next $100 \mathrm{~ms}$ (Fig. 8 B,E,H). Therefore, the visual signals that preceded the target blanking could have contributed to guide the correction saccades reported in Fleuriet and Goffart (2012) because the added delays did not exceed $100 \mathrm{~ms}$ (see their Figs. 6 and 7). Signals related to the expectation of target reappearance may not be necessary in generating the compensatory response. This conclusion neither refutes their existence nor the "here-and-now" hypothesis because most observations are consistent with this conjecture (see above). However, other experiments are required to test (and eventually refute) the hypothesis that the interceptive saccades are driven by a dynamic command encoding the current spatiotemporal position of the target.

\section{Where do the saccades land in response to a moving target?}

Our study provides evidence that the visuo-saccadic motor system extrapolates a landing position from transient signals of a moving target. In addition to their sensitivity to the target eccentricity, the saccades land on a position that depends more upon the speed of the target than the duration or amplitude of its displacement. For identical overall target displacement, the landing position is more eccentric with the faster target. When the target moves with a constant speed, the saccades land along the target path (Fig. 8). Such a result could be considered as evidence for an efficient predictive performance. However, two points lead us to cautiously interpret this observation. First, the block design of our experiments likely reduced the uncertainty about the target path and its dynamics. Second, this predictive-like performance depends upon the constancy of target speed. Indeed, when the target decelerates, the saccades do not land where the target would be within the next $100 \mathrm{~ms}$; they largely overshoot the target location, even those with the longest latency. When the target accelerates, the saccades with the shortest latencies under- shoot the target location (Figs. 8, 9). Intriguingly, the endpoints are scattered along a path that depends upon their landing time with a relation the slope of which differs from the average speed of the target but approximate its final speed (Fig. 8). When the speed increases from 0 to $40 \%$, the average slopes are 41,24 , and $35 \%$ s (in Monkey G, A, and M, respectively). When it is constant, the slopes are 21,18 , and $22 \%$, respectively, and, when it decreases from 40 to $0 \%$, the slopes are $11.3,6.3$, and $8.5^{\circ} / \mathrm{s}$, respectively. The extrapolation seems to mimic the target dynamics and sustains it for at least an additional $100 \mathrm{~ms}$. Initially, the interceptive saccades can be inaccurate (Fig. 9) and processes subtending their adaptation (Hopp and Fuchs, 2004; Havermann et al., 2012) could subsequently proceed via cerebello-reticular (Kojima et al., 2008; Quinet and Goffart, 2015) and cerebello-thalamic influences (Gaymard et al., 2001). Through neural processes that remain mostly unknown, the visuo-oculomotor system learns to incorporate the dynamics of objects embedded in its environment (Bourrelly et al., 2014), extending to shorter time scales the adaptive process by which the environment is imprinted within the anatomo-functional organization of the nervous system (Lorenz, 1977).

\section{References}

Albright TD, Desimone R (1987) Local precision of visuotopic organization in the middle temporal area (MT) of the macaque. Exp Brain Res 65:582592. Medline

Anderson RW, Keller EL, Gandhi NJ, Das S (1998) Two-dimensional saccade-related population activity in superior colliculus in monkey. J Neurophysiol 80:798-817. Medline

Arnstein D, Junker M, Smilgin A, Dicke PW, Thier P (2015) Microsaccade control signals in the cerebellum. J Neurosci 35:3403-3411. CrossRef Medline

Barmack NH (1970) Modifications of eye movements by instantaneous changes in the velocity of visual targets. Vision Res 10:1431-1441. CrossRef Medline

Bourrelly C, Quinet J, Goffart L (2014) Unsupervised dynamic morphing of a spatiotemporal visual event during its oculomotor tracking [abstract]. J Vis 14:492. CrossRef

Cassanello CR, Nihalani AT, Ferrera VP (2008) Neuronal responses to moving targets in monkey frontal eye fields. J Neurophysiol 100:1544-1556. CrossRef Medline

Dale A, Cullen KE (2015) Local population synchrony and the encoding of eye position in the primate neural integrator. J Neurosci 35:4287-4295. CrossRef Medline

Daniel PM, Whitteridge D (1961) The representation of the visual field on the cerebral cortex in monkeys. J Physiol 159:203-221. CrossRef Medline

de Brouwer S, Yuksel D, Blohm G, Missal M, Lefèvre P (2002) What triggers catch-up saccades during visual tracking? J Neurophysiol 87:1646-1650. Medline

Dudai Y (2009) Predicting not to predict too much: how the cellular machinery of memory anticipates the uncertain future. Philos Trans R Soc Lond B Biol Sci 364:1255-1262. CrossRef Medline

Fleuriet J, Goffart L (2012) Saccadic interception of a moving visual target after a spatiotemporal perturbation. J Neurosci 32:452-461. CrossRef Medline

Fleuriet J, Hugues S, Perrinet L, Goffart L (2011) Saccadic foveation of a moving visual target in the rhesus monkey. J Neurophysiol 105:883-895. CrossRef Medline

Fuchs AF (1967) Saccadic and smooth pursuit eye movements in the monkey. J Physiol 191:609-631. CrossRef Medline

Gandhi NJ, Keller EL (1999) Comparison of saccades perturbed by stimulation of the rostral superior colliculus, the caudal superior colliculus, and the omnipause neuron region. J Neurophysiol 82:3236-3253. Medline

Gaymard B, Rivaud-Péchoux S, Yelnik J, Pidoux B, Ploner CJ (2001) Involvement of the cerebellar thalamus in human saccade adaptation. Eur J Neurosci 14:554-560. CrossRef Medline

Goffart L, Quinet J, Chavane F, Masson GS (2006) Influence of background 
illumination on fixation and visually guided saccades in the rhesus monkey. Vision Res 46:149-162. CrossRef Medline

Goffart L, Hafed ZM, Krauzlis RJ (2012) Visual fixation as equilibrium: evidence from superior colliculus inactivation. J Neurosci 32:1062710636. CrossRef Medline

Goffart L, Quinet J, Bourrelly C (2014) Foveating a moving target here-andnow [abstract]. J Vis 14:495. CrossRef

Goossens HH, Van Opstal AJ (2000) Blink-perturbed saccades in monkey. I. Behavioral analysis. J Neurophysiol 83:3411-3429. Medline

Guerrasio L, Quinet J, Büttner U, Goffart L (2010) Fastigial oculomotor region and the control of foveation during fixation. J Neurophysiol 103: 1988-2001. CrossRef Medline

Hafed ZM, Krauzlis RJ (2012) Similarity of superior colliculus involvement in microsaccade and saccade generation. J Neurophysiol 107:1904-1916. CrossRef Medline

Havermann K, Volcic R, Lappe M (2012) Saccadic adaptation to moving targets. PLoS One 7:e39708. CrossRef Medline

Hopp JJ, Fuchs AF (2004) The characteristics and neuronal substrate of saccadic eye movement plasticity. Prog Neurobiol 72:27-53. CrossRef Medline

Johnston A (1986) A spatial property of the retino-cortical mapping. Spat Vision 1:319-331. CrossRef Medline

Keller E, Johnsen SD (1990) Velocity prediction in corrective saccades during smooth pursuit eye movements in monkey. Exp Brain Res 80:525531. Medline

Klam F, Petit J, Grantyn A, Berthoz A (2001) Predictive elements in ocular interception and tracking of a moving target by untrained cats. Exp Brain Res 139:233-247. CrossRef Medline

Kojima Y, Iwamoto Y, Robinson FR, Noto CT, Yoshida K (2008) Premotor inhibitory neurons carry signals related to saccade adaptation in the monkey. J Neurophysiol 99:220-230. Medline

Lisberger SG (1998) Postsaccadic enhancement of initiation of smooth pursuit eye movements in monkeys. J Neurophysiol 79:1918-1930. Medline

Lorenz K (1977) Behind the mirror: a search for a natural history of human knowledge. London: Methuen.

McIlwain JT (1976) Large receptive fields and spatial transformations in the visual system. Int Rev Physiol 2:223-248.

McPeek RM, Keller EL (2001) Short-term priming, concurrent processing, and saccade curvature during a target selection task in the monkey. Vision Res 41:785-800. CrossRef Medline

McPeek RM, Skavenski AA, Nakayama K (2000) Concurrent processing of saccades in visual search. Vision Res 40:2499-2516. CrossRef Medline
Mettens P, Godaux E, Cheron G, Galiana HL (1994) Effect of muscimol microinjections into the prepositus hypoglossi and the medial vestibular nuclei on cat eye movements. J Neurophysiol 72:785-802. Medline

Newsome WT, Wurtz RH, Dürsteler MR, Mikami A (1985) Deficits in visual motion processing following ibotenic acid lesions of the middle temporal visual area of the macaque monkey. J Neurosci 5:825-840. Medline

Quinet J, Goffart L (2015) Cerebellar control of saccade dynamics: contribution of the fastigial oculomotor region. J Neurophysiol 113:3323-3336. CrossRef Medline

Rashbass C (1961) The relationship between saccadic and smooth tracking eye movements. J Physiol 159:326-338. CrossRef Medline

Robinson DA (1965) The mechanics of human smooth pursuit eye movement. J Physiol 180:569-591. CrossRef Medline

Schiller PH, Sandell JH (1983) Interactions between visually and electrically elicited saccades before and after superior colliculus and frontal eye field ablations in the rhesus monkey. Exp Brain Res 49:381-392. Medline

Segraves MA, Goldberg ME, Deng SY, Bruce CJ, Ungerleider LG, Mishkin M (1987) The role of striate cortex in the guidance of eye movements in the monkey. J Neurosci 7:3040-3058. Medline

Sparks DL, Mays LE (1983) Spatial localization of saccade targets. I. Compensation for stimulation-induced perturbations in eye position. J Neurophysiol 49:45-63. Medline

Sparks DL, Holland R, Guthrie BL (1976) Size and distribution of movement fields in the monkey superior colliculus. Brain Res 113:21-34. CrossRef Medline

Sparks DL, Mays LE, Porter JD (1987) Eye movements induced by pontine stimulation: interaction with visually triggered saccades. J Neurophysiol 58:300-318. Medline

Tootell RB, Switkes E, Silverman MS, Hamilton SL (1988) Functional anatomy of macaque striate cortex. II. Retinotopic organization. J Neurosci 8:1531-1568. Medline

Van Essen DC, Newsome WT, Maunsell JH (1984) The visual field representation in striate cortex of the macaque monkey: asymmetries, anisotropies, and individual variability. Vision Res 24:429-448. CrossRef Medline

Walker MF, Fitzgibbon EJ, Goldberg ME (1995) Neurons in the monkey superior colliculus predict the visual result of impending saccadic eye movements. J Neurophysiol 73:1988-2003. Medline

Xu-Wilson M, Tian J, Shadmehr R, Zee DS (2011) TMS perturbs saccade trajectories and unmasks an internal feedback controller for saccades. J Neurosci 31:11537-11546. CrossRef Medline 